\title{
Enhancing Social Inclusion in Higher Education through Open Access to Digital Fabrication Laboratories
}

\author{
Covadonga Lorenzo, Epifanio Lorenzo \\ CEU University, Spain
}

\begin{abstract}
Promoting diversity, affirming equity and enhancing social inclusion in the classroom are goals shared by many European universities, but achieving these aims in the classroom is often hard to do. This paper presents a research study conducted at Fab Lab Madrid CEU, the digital fabrication laboratory based at CEU University to test innovative educational approaches that provides knowledge more accessible for all through new learning opportunities and open access to digital fabrication facilities. The study is based in the results obtained from four pilots, in which students engage with on-site and remote access to digital fabrication technologies through a platform designed for the European Union NEWTON Project. The platform is an innovative tool that provides educational content and new solutions for technology-enhanced learning to increase learner quality of experience for all.
\end{abstract}

\section{Introduction}

Enhancing social inclusion in Higher Education has become an imperative in our country to avoid the risk of social exclusion and reduce drop-out rates of studies that nowadays is affecting youth between 18 and 24 years in Spain. This situation especially affects students with disabilities and learning difficulties, as well as young students of vulnerable social environments in disadvantage, that are the groups to which our research study is focused.

\section{Disable Students}

A recent study carried out in more than fifty Spanish universities about the degree of inclusion of people with disabilities in the university system [1] shows that only about $5 \%$ of people with disabilities have university studies, despite that the 2020 European strategy is talking of a $40 \%$. These figures show that, despite the effort carried out by the Spanish universities in the last years to promote diversity and improve access of all persons with special needs in the university, it is still necessary to adopt measures to reduce early school drop-outs, promote access and guarantee higher education adapted to future needs.
A report on employment of people with disabilities published by the Spanish National Institute of Statistics (INE) in 2017, [2] indicates that the most significant feature of this group of students is their low labor participation: $35 \%$ activity rate compared to $78 \%$ for the people without disabilities. The European Disability Strategy 2010-2020 [3] indicates that "quality employment ensures economic independence, promotes personal achievement and offers the best protection against poverty and social exclusion". Moreover, the Convention on the Rights of Persons with Disabilities declares that "states will ensure an inclusive education system at all levels, including Higher Education, to fully develop the human potential and the sense of dignity and selfesteem and reinforce respect for human rights, fundamental freedoms and human diversity". [4]

Some researchers $[5,6]$ have shown that access to higher education will make possible for people with disabilities to participate in a diverse society, developing their maximum potential and improving the expectations of achieving quality employment, which allows independence and freedom in decisionmaking. Other studies [7, 8] highlight that the training of people with intellectual disabilities in the university environment, with a degree issued by the University, positively affects their employment, involves a mutual growth for students with and without disabilities and favor their professional inclusion and as a result, sustenance, autonomy, and a decrease in the need for assistance and support.

However, it is also stated by some researchers [9, 10] that best programs may be required to address success and retention at the university level, as well as making curriculum adaptations, training professors and improving accessibility involving all the university community.

\subsection{Disadvantaged Students}

Spain is the second country of the European Union (EU) in Early School Leaving (AEP), with a rate of $19 \%$ of young people between 18 and 24 years old, who have left the education system prematurely, having completed at the very least the first cycle of Secondary Education (ESO). However, our country has managed to reduce the school dropout rate in the last decade from $30 \%$ to $19 \%$. On the other hand, the rate of people between 30 and 34 
years old who have completed their higher education was $39 \%$ in the European Union while Spain registers a rate of $40 \%$. [11]

Social class is the factor with the highest incidence in the risk of dropping out of school, and is attributable by $50 \%$. This percentage is explained by issues such as economic difficulties, but mainly by "the absence of family and institutional support networks". [12] Unfortunately, educational exclusion is one of the main problems of social exclusion. Moreover, if we consider, not only disadvantages but learning difficulties and disabilities as potential limitations for college success, the number of students in risk of education exclusion increases ever more, as students with some kind of disability are an at-risk population, sometimes absent from the diversity groups.

Digital Fabrication Laboratories (Fab Labs) have been proved [13-16] as attractive models of education, particularly as places to provide training in a wide range of areas from design thinking to product development. Yet, less research exists on how Fab Labs can affect student's interaction to promote diversity, social inclusion and equity at the university level. However, some researchers [17] suggested that using digital fabrication technologies made university students keener to self-learning and that the social interaction and learning with and from multiple team members can be a very efficient way of studying and promoting equity and diversity.

\section{Research Objectives and Methodology}

In this context, our institution is working to be permeable to this environment, promoting an inclusive education that contributes to the construction of a cohesive and respectful society that follows the principle of equal opportunities and nondiscrimination. The premise for our work is promoting diversity and increasing equity for university students; providing instruction and open access to digital fabrication facilities for young people of vulnerable social environments in disadvantage and students with disabilities and learning difficulties, and enhancing social inclusion and social cohesion in the education system at university level through the use of new technologies. The aim is to find new educational approaches and materials for inclusive activities in the university's courses; enhance the capacities of university students for design and fabrication, and improve professors' competences and practices for inclusive education.

The achievement of these objectives would not be possible without our participation in the research project NEWTON, [18-21] a large European Union Horizon 2020 project which designs and deploys innovative solutions for technology-enhanced learning that are validated with diverse audiences, including primary and secondary schools, universities and students with special educational needs in multiple European locations. The NEWTON technologies involve virtual teaching and learning laboratories (Virtual Labs), Augmented and Virtual Reality-enhanced learning, adaptive and personalized multimedia and multiple sensorial media (mulsemedia) delivery, gamification and remote access to Digital Fabrication Laboratories (Fab Labs).

These technologies are used in conjunction with different pedagogical approaches including gamebased, personalized and self-directed learning methods, such as flipped classroom, online problembased learning and e-practice testing. NEWTON also builds a management platform, called NEWTELP that allow learner and teacher interaction with content and courses and support dissemination of learning content to a wide audience. The aim is to improve learner quality of experience, learning process and learning outcomes. It is hoped that all this will make learning more attractive to the students, including students with special needs and disabilities studying at the university, which are the ones in which we will focus this research study.

To validate our approach a research study have been carried out based in the results obtained from four pilots, in which students engage with on-site and remote access to digital fabrication technologies thanks to the NEWTON Project platform.

\subsection{Schools and Participants}

Participants include students that come to the university classroom with different backgrounds and cultural contexts, some of them with disabilities and some others at risk of poverty and social exclusion. Schools and participants involved in the four pilots are listed below.

The first pilot involved fifteen students between eighteen and twenty-three years old with intellectual disabilities enrolled in the National Youth Guarantee System. They were studying the Advance Diploma on Universal Design at CEU University's Institute of Technology, a program specifically designed for young people with intellectual disabilities to provide quality and innovative university training and also a new qualification.

Students came from the Fundación Juan XXIII Roncalli, a reference foundation in the Community of Madrid, with more than fifty years of experience in the development of training and employment programs for disable students. The pilot involved the design and fabrication of merchandising items for the foundation, in order to apply concepts of Universal Design taught during theoretical classes. Students were provided with remote access to $3 \mathrm{D}$ printers through the NEWTON Project platform.

The second pilot was carried out with thirteen disable students coming from Fundación Oxiria, that 
were studying a Diploma on Floristry at ISEP CEU, an institute of professional studies. The challenge was the design and fabrication of bouquets of flowers using $3 \mathrm{D}$ printers and open design software. The aim was to show the applications of technology in this specific field of study, so that students could be able to introduce $3 \mathrm{D}$ printing technologies on their everyday work as florists.

The third pilot involved forty architectural students between the age of 19 and 24 that include thirty Peruvian students that come to our university from different backgrounds at risk of poverty and social exclusion. They were taught on how to use Fab Lab technologies on-site and remotely to analyze which one help better to improve their academic results and promote their social interaction. They had to design and build a real size prototype of an architectural summer pavilion using vinyl cutter and laser cutter machines, both on-site and remotely.

The last pilot involved fifteen students in disadvantage that come to our university from different foundations and ONGs thanks to a program called CEU Best, which provide university studies to young vulnerable related to International Cooperation and Development. The pilot involved the participation of the students in an International Cooperation Program that is running in our university to provide low-cost newborn incubators to some public hospitals in Sierra Leone (Africa). Students were trained on the use of design software to improve an existing prototype. After that, they were required to work collaboratively preparing and milling the pieces to build a new prototype using the NEWTON Project platform.

\subsection{Pilots testing the NEWTON Platform}

The four pilots carried out at the Fab Lab seek to promote students training and integration through activities at the university facilities. All are focused on introducing students to the use of digital fabrication technologies and offer remote access to Fab Lab machines, which includes laser cutters, 3D printers, vinyl cutters and milling machines. In addition to providing technical skills, pilots are designed to encourage social interaction, promoting diversity through a project-based approach, where students collaboratively work on the design and fabrication of a prototype.

Classes start with a short introductory talk on digital fabrication, showing possible applications of Fab Lab technologies in different disciplines and fields. After that, students are taught on the use of design software and the NEWTON Project platform that provide remote access to Fab Lab machines, so that students are able to fabricate their designs even if they are not physically in the laboratory. Finally, students are required to develop a group assignment to show the skills learned on the class and encourage interaction and problem solving collaboratively.

The first pilot seek to put universal design concepts into practice through the design and fabrication of merchandising items (keychains) including the logo of the Fundación Roncalli, according to the precepts of Universal Design. In order to design the products, students were trained on the use of an open source design software called FreeCAD. After that, they learned how to prepare in a $3 \mathrm{D}$ printer slicer application (Ultimaker Cura) the files to be printed, and finally, they learn to use the NEWTON Project platform to remotely 3D print their designs. Prototypes included suggestions for shapes that allow someone with a sight limitation to locate the correct key and to read the logo of the foundation, which was engraved on the keychain.

A similar workflow was followed on the second pilot. The challenge was the design and fabrication of 3D flowers using 3D Printers and open software. Students started designing the shapes through simple geometries and Boolean operations and after that, they were taught on how to $3 \mathrm{D}$ print the files. Finally, pieces were made using the NEWTON Project platform to get access to the 3D printer. After assembling all pieces, they got bouquets of flowers

The third pilot involved the design and fabrication of an architectural pavilion, using two specific technologies: laser and vinyl cutters machines. It was organized in three stages. The first one was focused on the design of the structure using Grasshopper, an open-source parametric software that allows us to train students on how to design using parameters and explicit functions, which requires a different way of thinking than simple 3D modeling. Then students were requested to fabricate small-scale prototypes of their designs using the NEWTON Project platform to remotely access to Fab Labs' vinyl cutter machines. After that, one design was selected to be built in real size using laser cutter machines on-site.

The last pilot was focused on the fabrication of a low-cost incubator for public hospitals based in Sierra Leone (Africa). The pilot was organized in two activities: the first one was related to design procedures and focuses on the implementation of an open-source baby incubator design in a computeraided design software to improve the existing prototype attending the prerequisites stated by the hospital. The second activity targeted the digital fabrication of the previous designs; first, using digital fabrication machines on-site and after that, through the NEWTON Project platform.

Students were required to work collaboratively during a week to prepare and send their files through the platform that allows students to select the Fab Lab machine to be used and the material to be milled. The platform is designed to assign all parameters needed to mill the pieces. Finally, 
students meet together to assemble the incubator and discuss results with instructors.

\subsection{Data Collection}

The core of the evaluation procedure employed in the four pilots was developed by the NEWTON project's Pedagogical Assessment Committee (PAC), that provided templates, guidelines and questionnaires. First of all, a Learner Demographic questionnaire was used to collect information about learners, such as gender, age or background.

Secondly, Learner Motivation questionnaires (pre and post activities) were used to assess learner's perception toward activities and also to test the NEWTON Project platform impact on student's social interaction during the pilot.

And finally, a Learner Usability questionnaire was handed-out to assess learners feeling about the usability of Fab Lab machines on-site and remotely through the NEWTON Project platform. Besides, instructors carried out learner observational assessment during activities.

The scope of the four case studies was to evaluate the learning Impact on students on the four pilots; to test the impact of the methodology on students social inclusion and finally, to validate the usability of the NEWTON platform in comparison with the usual Fab Lab workflow, in order to assess whether it is worthwhile to implement the use of this technology as an educational tool.

\section{Findings}

The research study evaluates the impact of the Fab Lab pilots on students' learning impact and social inclusion. It also tests the usability of the NEWTON Project platform to remotely access Fab Lab facilities.

Regarding the learning impact, a comparison between the grades of students using Fab Lab machines for the first time following the usual workflow (on-site) and using machines remotely through the NEWTON platform are promising, as they revealed significant improvements.

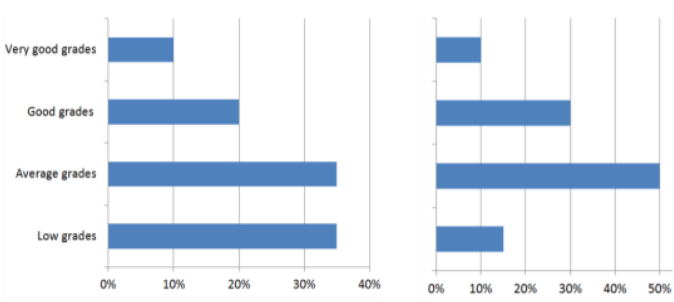

Figure 1: Student's grades using Fab Lab tools on-site (left) and remotely through NEWTON platform (right)

Low grades' percentages decreased to a $15 \%$ of students, while the number of students with average grades grew to a $50 \%$. Besides, $30 \%$ of participants got good results and $10 \%$ very good ones.

In relation to the impact of the NEWTON Project platform on student's social inclusion, the results are also promising. Questionnaires reflected that half the students didn't feel completely integrated in conventional classes at the university. Specifically, $10 \%$ of students stated they didn't feel integrated at all and $40 \%$ answered they felt slightly integrated. However, $50 \%$ of students said they felt completely integrated on classes.

The percentage of students that felt integrated during the pilots increased to reach a percentage of $70 \%$, while $10 \%$ of students kept feeling slightly integrated. Surprisingly, $20 \%$ of students adopted the role of leaders of their own groups taking initiatives and encouraging other students to engage on class activities and discussions interacting with the rest of students.
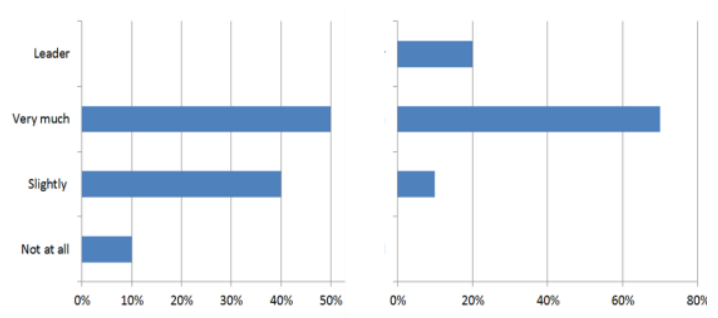

Figure 2: Degree of social inclusion at the conventional university classes (left) and during the pilots (right)

Regarding the Learner Usability questionnaire students had to answer four types of questions referred to usefulness, effectiveness, ease of use and ease of learning without instructions.
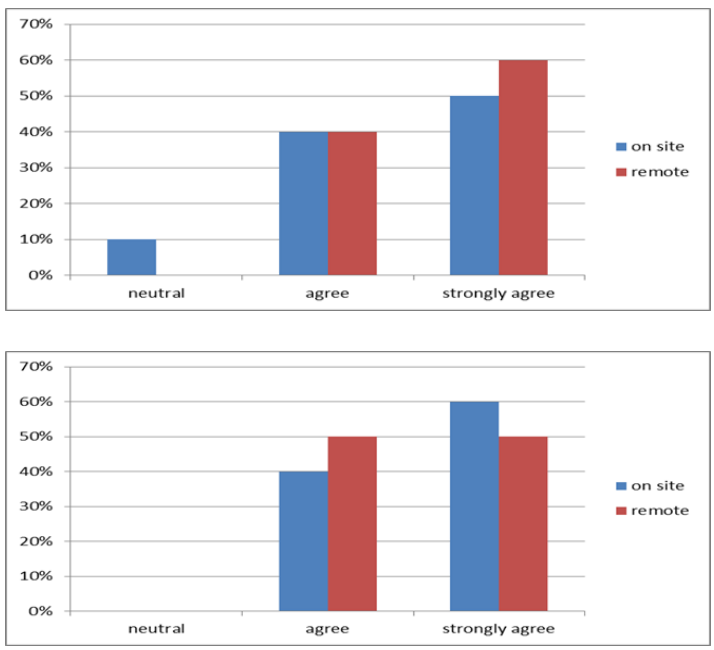

Figure 3: Effectiveness (above) and usefulness (below) of Fab Lab tools used on-site and remotely through the NEWTON Project platform

In relation to usefulness and effectiveness, students were asked if Fab Lab technologies (on-site 
and remote) helped them to be more effective. As it is shown in the tables included below, similar answers were given from the students when asked about the effectiveness and usefulness of Fab Lab technologies used on-site and remotely through the NEWTON Project platform.

When asked about the ease of use, $70 \%$ of students "Strongly agree" on the ease of use of Fab Lab machines through the NEWTON platform versus $20 \%$ of students who agreed on that in relation to the use of Fab Lab machines on-site. Promising results were also found when students were asked about the use of the platform. $60 \%$ of students "Strongly agree" on the ease of use.
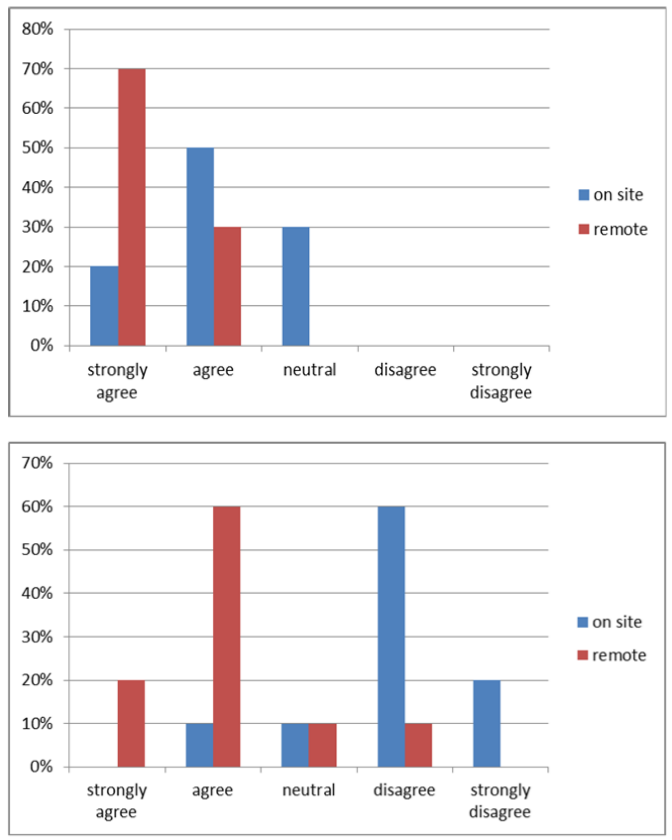

Figure 4: Ease of use (above) and use without instruction (below) of Fab Lab tools used on-site and remotely through the NEWTON Project platform.

Observation carried out by instructors during pilots revealed that students felt more integrated in Fab Lab activities carried out during the pilots than in conventional classes. When asked about their feeling of belonging to the university community, one of the students stated "Working collaboratively allowed me to feel more integrated with my classmates as part of a team". Another student stated: "When working in group, you feel more confident to intervene in class on behalf of a supporting team".

\section{Discussion and Conclusion}

Results reveal that the use of the NEWTON Project platform to remotely access Fab Lab machines is a powerful tool to be used during the classes, that not only help students in acquiring technical skills, but also in allowing social interaction, promoting equity and affirming diversity in the classroom. Findings also indicate that learners are more motivated when engaging in more personalization, collaboration and new pedagogical approaches that run between on-site and remote learning with the help of instructors who are confident in creating a richer educational environment available for all. Analysis has shown high degrees of student's motivation and satisfaction with social experiences on the four pilots. There were also found out high degrees of belongings and low degrees of social exclusion felt by students with disabilities, as well as good degrees of success with the use of digital fabrication technologies.

Although this is an on-going program, it seems that the first results are promising and the use of the NEWTON Project platform in Fab Labs helps to promote inclusive initiatives within the university community, contributing to the inclusion of young people of vulnerable social environments in disadvantage and students with disabilities and learning difficulties at the university level.

\section{References}

[1] VV.AA. Universidad y discapacidad. III Estudio sobre el grado de inclusión del sistema universitario español respecto de la realidad de la discapacidad. Fundación Universia and Comité Español de Representantes de Personas con Discapacidad (CERMI), 2016. (online). http://riberdis.cedd.net/handle/11181/5199.

[2] VV.AA. Empleo de las Personas con Discapacidad. Instituto Nacional de Estadística, 2017. (online) Retrieved from: https://www.ine.es/welcome.shtml.

[3] Comisión Europea. Estrategia Europea sobre Discapacidad 2010-2020. Brussels, 2010 (online). www.mscbs.gob.es/ssi/discapacidad/docs/estrategia_europ ea_discapacidad_2010_2020.pdf.

[4] Naciones Unidas. Convención sobre los Derechos de las Personas con Discapacidad. (online) Retrieved from: http://www.un.org/spanish/disabilities/default.asp?id=497.

[5] M. L. Gomes-Machado; F. H. Dos Santos; T. Schoen; B. Chiari, "Effects of Vocational Training on a Group of People with Intellectual Disabilities", Journal of Policy and Practice in Intellectual Disabilities 13 (1), March 2016, pp. 36-40.

[6] H. L. Kleinert; M. M. Jones; K. Sheppard-Jones; B. Harp and E. M. Harris, "Students with Intellectual Disabilities Going to College? Absolutely!", Teaching Exceptional Children, vol. 44, n. 5, 2012, pp. 26-35.

[7] R. Cerrillo Martín; D. Izuzquiza Gasset and I. Egido Gálvez, "Inclusión de jóvenes con discapacidad intelectual en la Universidad", Revista de Investigación en Educación, n. 11 (1), 2013, pp. 41-57. (online) Retrieved from: http://webs.uvigo.es/reined. 
[8] A. G. Harrison. "Mild Intellectual Disability at the Post-secondary Level: Results of a Survey of Disability Service Offices", Exceptionality Education International, vol. 23, n. 1, 2013.

[9] A. Rodríguez-Martín; E. Álvarez-Arregui, "University Students with Disabilities in Universities. A Study of their Inclusion", Revista Complutense de Educación vol. 25 n. 2, 2014, pp. 457-479.

[10] E. Omaña; N. Alzolar, "Pedagogical strategies for the inclusion of the student with disabilities", Educación en contexto, vol. 3, n. 6, 2017, pp. 84-109.

[11] L. Serrano, A. Soler and L. Hernández, 2017. El abandono educativo temprano: análisis del caso español, Instituto Valenciano de Investigaciones Económica, Spain.

[12] A. Tarabini, J. Jacovkis and A. Montes, 2017. Los factores de la exclusión educativa en España: Mecanismos, perfiles y espacios de intervención, UAB \& UNICEF, Spain.

[13] P. Blikstein, Digital Fabrication and 'Making' in Education: The Democratization of Invention in FabLabs. J. Walter \& C. Büching (Eds.), Bielefeld, 2013.

[14] C. Lorenzo, "Improving Learning Process Through Digital Fabrication Technologies," In Proceedings of the International Conference on Education and New Learning Technologies (EDULEARN17), Barcelona, Spain, 2017, pp. 6069-6076.

[15] C. Lorenzo, E. Lorenzo, "On How to Empower Architectural Students through the Use of Immersive Technologies," In Proceedings of the International Conference on Education and New Learning Technologies (EDULEARN19), Palma de Mallorca, Spain, 2019.

[16] C. Lorenzo and E. Lorenzo, "Advanced Education through Innovation via Remote Access to Digital Fabrication Technologies," In Nueva Enseñanza Superior a partir de las TIC, Editorial Gedisa, Barcelona, 2018.

[17] P. Eversmann. 2017. "Digital Fabrication in Education. Strategies and Concepts for Large-scale Projects". Proceedings of the 35th eCAADe Conference, volume 1, Portugal, pp.333-342.

[18] M. A. Togou, C. Lorenzo, E. Lorenzo, G. Cornetta and G.-M. Muntean, "Raising Students' Interest in STEM Education Via Remote Digital Fabrication: An Irish Primary School Case Study," In Proceedings of the 10th annual International Conference on Education and New Learning Technologies (EDULEARN 18), Palma de Mallorca, Spain, 2018, pp. 2835-2840.

[19] C. Lorenzo, E. Lorenzo, "Advanced Education through Innovation via Remote Access to Digital Fabrication Technologies," In Nueva Enseñanza Superior a partir de las TIC, Editorial Gedisa, Barcelona, 2018.

[20] C. Lorenzo, E. Lorenzo, G. Cornetta, G.-M. Muntean and M. A. Togou, "Designing, Testing and Adapting to Create a Distributed Learning Program In Open Design and Digital Fabrication," In Proceedings of the
International Conference of Education, Research and Innovation (ICERI), Seville, Spain, 2018, pp. 8097-8105.

[21] G. Cornetta, A. Touhafi, F. J. Mateos and G.-M. Muntean, "A Cloud-based Architecture for Remote Access to Digital Fabrication Services for Education," In Proceedings of the 4th IEEE International Conference on Cloud Computing Technologies and Applications CLOUDTECH, Brussels, Belgium, 2018.

\section{Acknowledgements}

NEWTON project has received funding from the European Union's Horizon 2020 Research and Innovation program under Grant Agreement no. 688503. 